\title{
Presenteeism and work ability: development of the Persian version of the Stanford Presenteeism Scale (P-SPS-6) and measurement of its psychometric properties
}

Fatemeh Abdi ${ }^{1}$, Mehdi Jahangiri ${ }^{1}$, Mojtaba Kamalinia ${ }^{1}$, Rosanna Cousins ${ }^{2}$ and Hamidreza Mokarami ${ }^{3 *}$

\begin{abstract}
Background: Presenteeism is recognized in Iran's hospitals, however little research has been done to understand and tackle the phenomenon because of a lack of valid tools to measure presenteeism. This study aimed to develop a Persian version of the Stanford Presenteeism Scale (SPS-6) and measure its psychometric properties. Another goal was to examine the relationship between presenteeism and work ability using a sample of 250 nurses.

Methods: The forward-backward translation process and cross-cultural adaptation of the scale were performed according to a standard method. The psychometric properties of the scale were measured using face and content validity, construct validity based on confirmatory factor analysis (CFA), and internal consistency. Work ability score (WAS) was used to assess discriminative validity and examine the relationship between presenteeism and work ability. Measures of Job Satisfaction and Emotional Exhaustion were used to assess convergent validity with the developed presenteeism scale.

Results: Mean content validity index and content validity ratio were 1 and 0.93 respectively. CFA verified the twodimensional structure of the scale. Cronbach's alpha was 0.77 . There were positive relationships between P-SPS- 6 and Job Satisfaction, and P-SPS-6 and WAS. There was a significant negative relationship between P-SPS-6 and Emotional Exhaustion.

Conclusion: Our findings suggested that the P-SPS-6 had appropriate psychometric properties for studying presenteeism in employees using the Persian language. Given the negative relationship between presenteeism and work ability and the negative consequences associated with it, it is necessary to regularly evaluate this stressor and to emphasize purposeful intervention programs to control or reduce it.
\end{abstract}

Keywords: Presenteeism, Absenteeism, Work ability, Job satisfaction, Emotional exhaustion, Nurses

*Correspondence: hamidreza.mokarami@yahoo.com

${ }^{3}$ Department of Ergonomics, School of Health, Shiraz University

of Medical Sciences, Shiraz, Iran

Full list of author information is available at the end of the article

\section{Background}

Managers and organizations are concerned with ways to improve job performance and reduce costs. One way to increase productivity is to minimize absenteeism [1]. However, even when employees are physically present at work, they may experience a decrease in productivity and the quality of work; a phenomenon which is called presenteeism [1-4]. Presenteeism is defined as a person being 
present at work, but due to health problems their usual job performance is decreased $[2,5]$. Counter intuitively, attending work when one is ill-presenteeism-can be more detrimental to an organization than absenteeism, as evidenced by robust reports that presenteeism reduces productivity as much as three times more than absenteeism [6]. Similarly, the cost of presenteeism to an organization is significantly greater than for absenteeism [7]. This can explain why managers and researchers are concerned and now paying more attention to presenteeism.

Presenteeism has been associated with other negative consequences besides reduced productivity. These include reduced quality of work, job neglect, and increased errors [8-10]. Its effects in occupations such as healthcare workers dealing with vulnerable populations can be extremely serious $[11,12]$. For example, nurses who work during illness may not work to a satisfactory standard to the extent of increasing risk of errors that could cause harm, or even endanger life. Similarly, those working with infection risk spreading disease to patients, visitors, and colleagues $[4,13]$.

The high rates of presenteeism in medical staff have been attributed to specialized roles, lack of work force, low possibility of replacement, and a strong sense of duty towards patients $[11,13,14]$. Indeed, it has recently been reported that the level of presenteeism in hospital doctors is between 53 and 86\% [15]. Research has also estimated the cost of presenteeism among nurses in the United States at about $\$ 2$ billion to $\$ 13$ billion annually, using 2009 prices [4]. For these reasons, the majority of studies on presenteeism have targeted the healthcare sector $[11,12,16]$.

Job satisfaction is an important factor in the lives of health care staff because it can affect quality of care, productivity, and performance $[17,18]$. Many studies have examined the relationship between presenteeism and job satisfaction, however there is no consensus in the findings $[19,20]$. Some studies have reported a positive relationship between presenteeism and job satisfaction $[20,21]$, while the results of other studies have indicated a negative relationship [22-24]. That is, individuals who report presenteeism, often also assess their work environment as stressful and unsatisfactory [24]. Furthermore, a longitudinal study by Baker-McClearn et al. indicates the negative association of presenteeism with job satisfaction is due to a lack of sufficient opportunity for recovery of health [22]. Therefore, going to work during times of illness and poor health can have negative consequences such as lower job satisfaction and work engagement [24].

Emotional exhaustion is another subjective variable that can occur following a decrease in employees' job satisfaction [25, 26]. Emotional exhaustion can also be the result of long-term presenteeism [27]. In this regard, research studies indicate that presenteeism leads to exhaustion and depersonalization and predicts job absence [28]. Demerouti et al. studied nurses and indicated that presenteeism was a dangerous organizational behavior that could lead to long-term burnout [29]. This was probably because presenteeism does not give individuals a chance to recover, thereby leading to emotional exhaustion in the long term [27, 29].

Another consequence of health problems can be limited physical and functional capacities and thus reduced work ability [30]. Work ability is defined as an individual's occupational competence, health, and attitude required to meet their job demands [31]. Work ability is a concept of interest to researchers because if job demands are not commensurate with the physical and mental abilities of employees, it can lead to health and safety problems, increased costs, reduced productivity, early retirement [32], turnover [33], and increased absenteeism [34]. Finding factors that affect work ability can help managers increase their employees' work ability by controlling or modifying them [35]. There has been a lot of research in this area, and findings recognize that many factors such as age, job demands, job resources, health status, and psychological factors can affect work ability [36]. In addition, a longitudinal study by Gustafsson et al. showed a relationship between presenteeism and work ability, and that presenteeism can reduce work ability [35]. However, there has been no replication of this Swedish study in an Iranian population despite plenty of studies that have examined the relationship between sick leave and health problems [32].

The importance of presenteeism is recognized in Iran, however beyond a small qualitative study very little research has been done in this regard. One of the reasons for lack of progress is a lack of standard tools to measure presenteeism. Even though there are many tools have been developed internationally to measure presenteeism, they tend to be in English, and in that respect a barrier to use in Persian speaking populations. One of the most important and widely used tools is the Stanford Presenteeism Scale [11]. The scale was developed to measure employees' ability to concentrate and accomplish work while experiencing health problems. The 6-item version (SPS-6) of this scale was introduced by Koopman et al. [3]. Their goal was to incorporate the cognitive, emotional, and behavioral aspects of a group of employees into a practical, concise scale with excellent psychometric characteristics. The SPS-6 is short, easily applicable [11], suitable for all jobs [13] and it can evaluate the relationship between presenteeism, health problems, and employee productivity $[3,13]$. To the best of our knowledge, however, there has not yet been a validated 
translation of this scale into Persian. Therefore, this study followed two objectives:

1. Validating and localizing the SPS -6 scale in Persian to measure presenteeism

2. Investigating the relationship between the presenteeism and the work ability among Iranian nurses

\section{Methods \\ Design and study population}

This cross-sectional survey was supported by an available sample of hospital nurses July to December 2019. The inclusion criteria were to be a qualified nurse and have at least one year of work experience. Potential participants were provided with oral information about the study and its purpose; surveys were distributed among those who gave informed consent to participate.

267 nurses joined the study. 17 participants who did not fully complete the survey were excluded providing a final sample of 250 participants. This was more than sufficient to examine the psychometric properties of the Persian SPS- 6 questionnaire according to the robust quality criteria for measurement properties for health questionnaires published by Terwee et al. [37].

\section{Measures}

The survey consisted of five sections. The first section measured demographic characteristics (sex, age, education level, work schedule, body mass index (BMI), tenure, and employment status). To ensure confidentiality and anonymity, demographic variables related to employee work (medical centers, wards, hospitals, etc.) were not collected. The other four sections were questionnaires to measure: (2) Presenteeism (SPS-6), (3) Job Satisfaction, (4) Work Ability, and (5) Emotional Exhaustion.

\section{Presenteeism}

The SPS- 6 consists of two dimensions. The first dimension is Completing Work which is related to the work outcomes associated with physical aspects of a job. The second dimension is Avoiding Distraction which is based on psychological aspects of the work process: the ability to focus on achieving work goals [11]. The items in this scale are scored on a five-point Likert scale ranging from 1 (strongly disagree) to 5 (strongly agree) with the third option (uncertain) considered a neutral score. Items 1,3 , and 4 are reverse scored. SPS- 6 score is the sum of the item scores (range 6-30). According to Koopman et al. [3], a high score indicates a low level of presenteeism. In other words, the higher the score, the greater that person's ability to concentrate and finish work, despite health problems. Presenteeism was measured using a
Persian version of Stanford Presenteeism Scale (P-SPS-6). The translation process is elaborated upon below.

\section{Job satisfaction}

Job Satisfaction was measured using the average score of the three-item Job Satisfaction subscale of the Michigan Organizational Assessment Questionnaire [38]. Items were scored on a six-point Likert scale ranging from 1 (strongly disagree) to 6 (strongly agree). The psychometric properties of the Persian version of this scale were confirmed by Mokarami [39].

\section{Work ability}

The Work Ability Score (WAS) was used to assess work ability. WAS is the first item in the Work Ability Index [31]; it considers current work ability compared with best work ability using a scale ranging from 0 (completely incapable of doing work) to 10 (fully capable of doing work). This simple and valid score has been used in many studies to evaluate work ability. The psychometric properties of WAS and its validity for assessing the work ability of Iranian employees were confirmed by Mokarami et al. [40].

\section{Emotional Exhaustion}

Emotional Exhaustion was assessed using the 9-item subscale of the Maslach Burnout Inventory [41]. Items are scored on a seven-point Likert scale ranging from 0 (never) to 6 (very-strong). The psychometric properties of the Persian Version Maslach Burnout Inventory were confirmed by Akbari et al. [42].

\section{Translation and cross-cultural adaptation of P-SPS- 6}

To preserve the intellectual property rights of the SPS-6 scale and obtain permission to translate it, we corresponded with the developers and obtained their permission. Based on the translation and cross-cultural adaptation process proposed by Beaton et al. [43], the scale was first translated through forward translation by two translators with a good command of English.

In the second step, members of the research team, along with the two translators, compared the two Persian versions of the scale with each other and discussed and resolved inconsistencies and ambiguities. Then, each of the six items was examined in terms of its meaning, and its cross-cultural equivalence and, where necessary, revised. Finally, a single Persian provisional version of the scale was developed.

In the third step (backward translation), the Persian provisional version was sent to two other English language experts, who were not aware of the English content of the scale and were asked to back-translate it into English (backward translation). The two English versions 
Abdi et al. BMC Psychol $\quad$ (2021) 9:120

Page 4 of 10

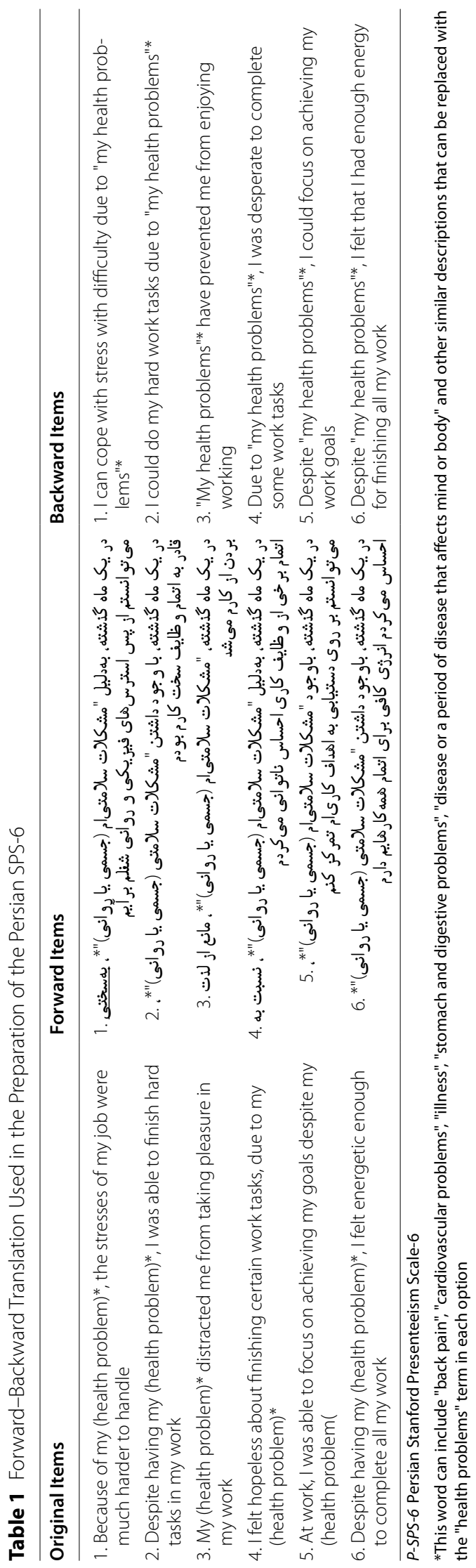


of the scale were then reviewed and merged again by the members of the research team, and a provisional English version of the scale was obtained. This version of the scale, along with the ambiguities and disagreements, was sent to the developers of the original version for further clarification and explanation. This version was approved after making the necessary amendments.

This version was provided to 25 nurses to resolve possible ambiguities. They were interviewed in person about their understanding of the perceptions of the scale items. The data from the interviews were discussed in an expert committee, including the members of the research team, two ergonomic and occupational health specialists, and two English translators, and the required modifications were applied to the items. Lastly, the final versions were prepared for measuring the psychometric properties. Forward-backward translations of the items are presented in Table 1.

\section{Measuring validity and reliability Face and content validity}

A group of 30 nurses and 10 university academics (ergonomics, occupational health, and health promotion) were asked to review the face validity and qualitative content validity of the scale. They consented to supporting the study after being given an explanation of its purpose. The anonymous presenteeism questionnaires were given to the participants to evaluate the statements in terms of comprehensibility, wording, interpretation, cultural issues, and clarity. After applying the recommended minor changes, quantitative content validity-including content validity index (CVI), and content validity ratio (CVR)-was assessed.

To evaluate CVI and CVR, the 10 university academics were asked to rate the relevance and necessity of each item, respectively. According to the guidelines [44], a CVI of greater than 0.79 is suitable, between 0.7 and 0.79 requires review, and less than 0.7 is unacceptable, and the item should be removed. According to Lawshe's table [45], items with a CVR greater than 0.62 (for ten experts) were considered necessary $(\mathrm{p}<0.05)$, and the items with a lower CVR were removed.

\section{Construct validity}

Confirmatory factor analysis (CFA) method with the maximum likelihood estimation (MLE) method was used to investigate the factorial structure of the scale. To evaluate the goodness of fit index in CFA, the root mean square error of approximation (RMSEA), the root mean square of residuals (RMR), the goodness of fit index (GFI), adjusted goodness of fit index (AGFI), the comparative fit index (CFI) and the chi-square/degrees of freedom ratio $\left(x^{2} / d f\right)$ were used $[46,47]$. If the CFI value is
0.95 or higher, the RMSEA is less than 0.08 , the RMR is close to zero, the GFI and AGFI values are 0.8 or 0.9 , and the $\chi^{2} / \mathrm{df}$ is less than 3 , the fit of the model is appropriate.

\section{Discriminative validity}

To evaluate the discriminative validity, the Mann-Whitney-Wilcoxon Test was used to compare the mean P-SPS-6 scores of people with low and high work ability. WAS scores below 8 are classified as inappropriate or inadequate work ability and WAS equal to or greater than 8 is considered as the appropriate work ability [40, 48]. Here, it was assumed that mean P-SPS-6 score for people with a low work ability score would be lower than that for those with a high work ability score [2].

\section{Convergent validity}

Convergent validity of the scale was confirmed by evaluating the relationship between P-SPS-6, Job Satisfaction, and Emotional Exhaustion scores by calculating Spearman's correlation coefficient. Job Satisfaction and Emotional Exhaustion scores were expected to be related to the P-SPS-6 score.

\section{Reliability}

The internal consistency of the P-SPS-6 scale was assessed using Cronbach's alpha. A coefficient of greater than 0.7 is considered favorable [49]. Moreover, the itemto-total correlation and Cronbach's alpha, if item deleted, were calculated separately. An item-to-total correlation greater than 0.3 for the individual scale items was considered optimal [2]. Presenteeism is a variable that depends on one's experience; it is not a consistent factor. For this reason, test-retest reliability of the scale was not evaluated in this study [3].

\section{Statistical analysis}

All data analysis procedures were performed using IBM SPSS Statistics and AMOS software, version 23. The Kolmogorov-Smirnov test was used to test the normality of data distributions. The significance level was set at the conventional $\mathrm{p}<0.05$. Floor and ceiling effects were considered in such a way that if more than $15 \%$ of the respondents obtained the minimum (6) or maximum score (30) on the P-SPS-6 scale [50].

\section{Results}

The mean age and work experience of the participants were $32.6 \pm 3.8$ years (range 22-54 years) and $8.79 \pm 7.3$ years (range $1-35$ years), respectively. Mean BMI was $19.91 \pm 3.1$. The demographic characteristics of the participants are presented in Table 2 . The mean and standard deviation of the P-SPS- 6 items are shown in Table 3. Only 3.2\% of the participants achieved the 
Table 2 Participants' socio-demographic and work-related factors $(N=250)$

\begin{tabular}{llr}
\hline Characteristics & N & \% \\
\hline Sex & 56 & 22.4 \\
Male & 194 & 77.6 \\
Female & & \\
Marital status & 103 & 41.2 \\
Single & 147 & 58.8 \\
Married & & \\
Education level & 14 & 5.6 \\
Associate & 225 & 90.0 \\
Bachelor & 11 & 4.4 \\
MSc and above & & \\
Workschedule & 42 & 83.8 \\
Day-work & 208 & \\
Three-shift & & 31.2 \\
Employment status & 78 & 68.8 \\
Permanent & 172 & \\
Temporary & &
\end{tabular}

minimum score (6) and none of them achieved the maximum score (30). These results indicated the absence of floor and ceiling effects.

\section{Validity}

Based on the results of measuring the content validity of the scale, the total CVI and CVR values of the scale were 1 and 0.93 , respectively, indicating the excellent content of the scale from the experts' point of view.

The path diagram of the CFA of the scale with standardized factor loadings of the items is shown in Fig. 1. The goodness-of-fit indices were as follows: $x^{2}$ was 12.22 , with eight degrees of freedom $(\mathrm{df}) ; \mathrm{X}^{2} / \mathrm{df}=1.53$. RMSEA $=0.046, \mathrm{RMR}=0.054, \mathrm{GFI}=0.98, \mathrm{AGFI}=0.96$, and $\mathrm{CFI}=0.99$. These indicators showed a very acceptable goodness-of-fit of the model. The factor loading values of the items measuring avoiding distraction and completing were in the range of $0.69-0.73$ and $0.51-0.74$

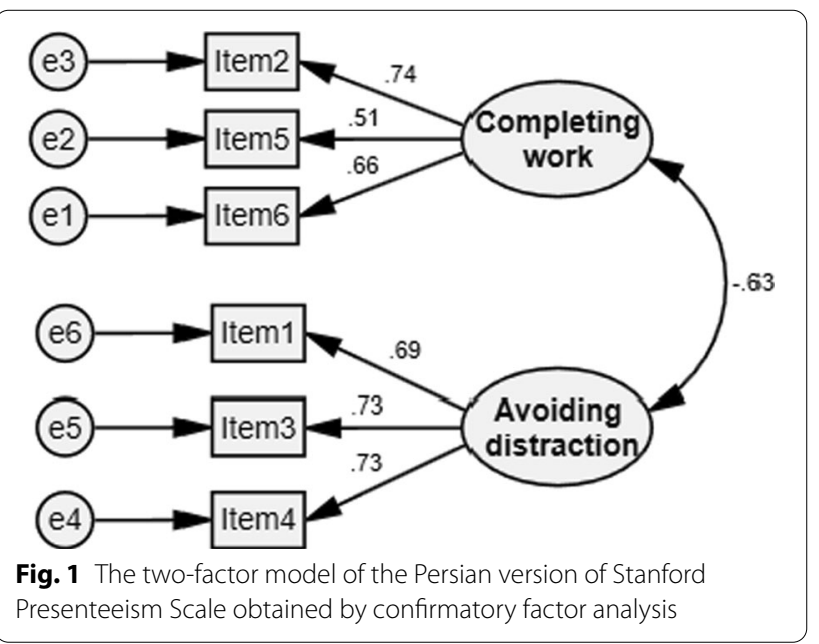

( $\mathrm{p}<0.001$ ), indicating the most desirable factor loading of the items in both dimensions of P-SPS-6 (see Table 3).

P-SPS-6 scores were significantly lower for people with poor work ability (mean $=15.38, \mathrm{SD}=4.84)$ compared with people with good work ability (mean $=19.30$, $\mathrm{SD}=4.48) \quad(\mathrm{p}<0.001$, Mann-Whitney-Wilcoxon Test $)$. These results indicated good divergent validity of P-SPS6. Moreover, there was a significant positive relationship between the P-SPS- 6 and WAI scores $(r=0.42, \mathrm{p}<0.001)$. Spearman's rho analyses also showed a positive relationship between PSPS- 6 score and job satisfaction score $(\mathrm{r}=0.32, \mathrm{p}<0.001)$, and a high negative correlation between P-SPS-6 score and emotional equation score $(\mathrm{r}=-0.46, \mathrm{p}<0.001)$. These results indicated a suitable convergent validity of P-SPS- 6 .

\section{Reliability}

The P-SPS-6 had good internal consistency: Cronbach's alpha $=0.77$. In addition, all the items of the scale had the required consistency. Corrected item-total correlation and Cronbach's alpha if item deleted for all the P-SPS-6 items are also presented in Table 3.

Table 3 Construct validity of P-SPS-6 $(N=250)$

\begin{tabular}{|c|c|c|c|c|c|c|}
\hline \multirow[t]{2}{*}{ Item } & \multirow[t]{2}{*}{ Mean (SD) } & \multirow{2}{*}{$\begin{array}{l}\text { Corrected item-total } \\
\text { correlations }\end{array}$} & \multirow{2}{*}{$\begin{array}{l}\text { Cronbach's Alpha if } \\
\text { item deleted }\end{array}$} & \multicolumn{3}{|c|}{ Confirmatory factor analysis } \\
\hline & & & & $\begin{array}{l}\text { Standardized regression } \\
\text { weight }\end{array}$ & Critical rate & $\mathbf{P}$ \\
\hline Q1 & $2.90(1.3)$ & .546 & .724 & .688 & 8.727 & $<.001$ \\
\hline Q2 & $2.62(1.2)$ & .551 & .723 & .745 & 7.231 & $<.001$ \\
\hline Q3 & $3.12(1.3)$ & .519 & .731 & .726 & 8.948 & $<.001$ \\
\hline Q4 & $2.57(1.3)$ & .593 & .711 & .735 & & \\
\hline Q5 & $2.60(1.1)$ & .351 & .770 & .507 & 6.147 & $<.001$ \\
\hline Q6 & $2.86(1.2)$ & .504 & .735 & .657 & & \\
\hline
\end{tabular}




\section{Discussion}

This study aimed to develop and evaluate the psychometric properties of a new Persian version of the SPS- 6 in a sample of 250 Iranian nurses. The translation and crosscultural adaptation process of the P-SPS-6 scale was performed using a standard and valid method. The psychometric properties of the scale were confirmed based on the assessments of the face and content validity, construct validity, convergent validity, discriminative validity, and internal consistency.

The face validity and qualitative content of the P-SPS-6 were assessed by experienced nurses and ergonomic, occupational health, and health promotion specialists. Necessary amendments were made to validate the scale based on the specialists' views. Subsequent assessment of the quantitative content validity of the scale based on CVR and CVI indicators indicated excellent content validity of the scale items.

In line with previous studies in other countries $[2,11$, $13,51]$, CFA showed that the new P-SPS-6 scale, like the original version, had a two-factor structure. The evaluative confirmatory factor analysis endorsed the twodimensional structure of the questionnaire. The first factor, Completing Work, included all the positive items, and the second factor, Avoiding Distraction, included all the negative items. However, the developers specifically recommended that the sub-scales scores are not considered separately, and only the overall scale score should be used to assess presenteeism of employees [3].

Assessment of internal consistency indicated optimal reliability of P-SPS-6, and indeed the calculated Cronbach's coefficient (0.77) was close to the coefficient calculated for the original version (0.80) [3] and in studies conducted in Italy (0.72) [13] and Portugal (0.83) [52]. To further examine the internal correlation of the scale, the item-total correlation of six items was evaluated, suggesting that all items had an acceptable correlation with the overall P-SPS-6 score.

The mean P-SPS-6 score was significantly lower among people with poor work ability compared to those who had higher work ability. This was a critical indicator of the discriminative validity of the P-SPS- 6 scale. That is, the results of the present study indicated that presenteeism had a significant correlation with reduced work ability. Whilst few studies have been conducted in this area, the robust longitudinal study by Gustafsson et al. [35] showed that presenteeism could have a causative negative effect on five health outcomes, most notably the effect of repeated presenteeism on reduced work ability and physical complaints. Hockey's theory [53] of the impact of stressful factors on work performance can explain the relationship between presenteeism and work ability. Presenteeism is regarded as a form of stressor that employees choose or are required to perform. In this situation, the person is physically or mentally ill, but for some reason, they have to go to work. As a result, they need to make more compensatory efforts to stay focused on their work, or to overcome symptoms that may negatively affect their work. This can increase employee stress and anxiety [10]. There is a strong correlation between presenteeism and stress [54]. On the other hand, the higher the stress, the lower would be the capacity to pay attention to environmental stimuli, and consequently this would lower work ability [10]. Previous studies have shown that nurses who are exposed to extreme stress in the workplace experience a greater reduction in work ability than those who experience less stress [55]. The results of a study by Koopman et al. [3], using the original version of the scale, showed that the mean score of SPS-6 was significantly lower in people who reported a disability, regardless of its relation to work, compared to employees who did not report disability. Hutting et al., however, found a significant difference only between people who reported work disability compared to people who reported non-work disability or no disability [2].

The correlation between presenteeism and reduced work ability, especially in the healthcare sector, is worrying. Following previous findings $[11,56]$ results of the present study suggested that more than half of nurses are present at work despite being ill. Nurses go to work even when they are ill for various reasons, such as knowing their work will not be covered, not wanting to impose extra work on colleagues, feeling responsible for their patients, and challenging economic consequences [11]. Nevertheless, presenteeism in nurses leads to a decrease in physical and mental health, followed by limited physical and functional capacities, resulting in reduced work ability [30]. With increasing presenteeism and reduced work ability, the possibility of errors also increases. Errors committed by health care workers can have irreversible consequences, such as endangering their own lives or the lives of patients. Niven and Ciborowska's [10] findings suggested that presenteeism is positively related to rates of both minor and serious errors such as giving the wrong medication or prescribing the wrong dose to patients. Therefore, it can be realizeded that interventions to reduce presenteeism are beneficial. They can help to increase the quality of work and productivity and reduce costs by maintaining and improving employees' ability to work.

The significant relationships we found between presenteeism and job satisfaction and emotional exhaustion replicate findings from previous studies [2, 3, 28]. For instance, similar to the present study, Vandenbroeck et al. [28] reported a correlation between presenteeism and emotional exhaustion and stated that high levels 
of emotional exhaustion among healthcare staff could increase presenteeism. According to the conservation of resources (COR) theory [57], in occupations such as nursing with demanding job requirements, the individual is forced to use additional physical, mental, and emotional resources. Since a person's resources are limited and presenteeism leads to long-term use of resources, there is no opportunity for resources to be recovered and resources are further diminished. This can lead to increased burnout, anxiety, and reduced productivity. On the other hand, the nursing job has high emotional requirements. When too many emotional resources are consumed, it will lead to emotional exhaustion and negatively affects the treatment of patients. As a result, it may be difficult for employees to dedicate themselves to work, and thus their work energy is reduced and they experience reduced work ability [16].

\section{Limitations}

In this study, self-reporting tools were used to consider the relationship of presenteeism and work ability. To ensure anonymity and confidentiality we could not knowingly collect information related to the workplace. It remains, however, that self-reporting tools are likely to produce biased results, even though, as Johns argues [58], it is difficult to measure presenteeism with a tool other than self-reporting instruments.

This study was performed among nurses in only one city. Therefore, caution should be exercised when interpreting and generalizing the findings regarding level of presenteeism. Future studies in Iran to assess the prevalence of presenteeism should go beyond one city and also include other occupations, as presenteeism is related to the nature of the job. A more comprehensive study of the relationship between variables such as work ability and emotional exhaustion with presenteeism is also important.

\section{Conclusion}

The results of the present study showed that the Persian version of the SPS-6 scale has suitable psychometric characteristics and can be used in future studies as a valid and efficient tool to assess the health and productivity of Iranian employees. The P-SPS- 6 whilst comprehensive, has only six items, and thus it can easily be used in a variety of workplaces, in initial screening of employees' health, and in staff surveys. The findings of the present study showed that presenteeism, as a stressor, has a high negative correlation with work ability. The high prevalence of presenteeism among nurses can have many negative consequences, such as reduced work ability, followed by reduced quality of work and increased costs. It is necessary to evaluate this stressor continuously and to emphasize purposeful intervention programs to control or reduce it.

\section{Abbreviations}

SPS-6: Stanford Presenteeism Scale; WAI: Work Ability Score; BMI: Body MasS Index; CVR: Content Validity Ratio; CVI: Content Validity Index; CFA: Confirmatory Factor Analysis; X2/df: Chi-Square/Degrees of Freedom Ratio; RMSEA: Root Mean Square Error of Approximation; GFI: Goodness-of-Fit Index; AGFI: Adjusted Goodness-of-Fit Index; CFI: Comparative Fit Index.

\section{Acknowledgements}

This study is part of the First author's MSc thesis and was conducted with financial support from Shiraz University of Medical sciences. The authors would like to thank the nurse for participating in the study.

\section{Authors' contribution}

HM, FA and MJ contributed to the Conceptualization, Project administration, Formal analysis and Writing - original draft. MK, and RC contributed to the Methodology and Writing —review and editing. All authors read and approved the final manuscript.

\section{Funding}

Shiraz University of Medical Sciences had funding support for data collection, study design, interpretation, and writing manuscript (Grant number 98010419691). The university did not participate in the writing of this paper, nor did it read or approve it.

\section{Availability of data and materials}

The datasets used and/or analysed during the current study are available from the corresponding author on reasonable request.

\section{Declarations}

Ethics approval and consent to participate

All procedures followed were in accordance with the ethical standards of the responsible committee of human experimentation (institutional and national) and with the Helsinki Declaration of 1975, as revised in 2000. Written informed consent was obtained from all participants for being included in the study. This research project was authorized by the Ethics Committee in Medical Researches of Shiraz University of Medical Sciences under the code of ethics IR.SUMS.REC.1398.653.

\section{Consent for publication}

Not applicable.

\section{Competing interests}

The authors declare that they have no competing interests.

\section{Author details}

${ }^{1}$ Department of Occupational Health and Safety Engineering, School of Health, Shiraz University of Medical Sciences, Shiraz, Iran. ${ }^{2}$ Department of Psychology, Liverpool Hope University, Liverpool, UK. ${ }^{3}$ Department of Ergonomics, School of Health, Shiraz University of Medical Sciences, Shiraz, Iran.

Received: 11 November 2020 Accepted: 12 July 2021

Published online: 17 August 2021

\section{References}

1. Schultz AB, Chen C-Y, Edington DW. The cost and impact of health conditions on presenteeism to employers. Pharmacoeconomics. 2009:27(5):365-78.

2. Hutting N, Engels JA, Heerkens YF, Staal JB, Nijhuis-Van der Sanden MW. Development and measurement properties of the Dutch version of the Stanford Presenteeism Scale (SPS-6). J Occup Rehabil. 2014;24(2):268-77. 
3. Koopman C, Pelletier KR, Murray JF, Sharda CE, Berger ML, Turpin RS, et al. Stanford presenteeism scale: health status and employee productivity. J Occup Environ Med. 2002;44(1):14-20.

4. Letvak SA, Ruhm CJ, Gupta SN. Nurses' presenteeism and its effects on self-reported quality of care and costs. Am J Nurs. 2012;112(2):30-8.

5. Lohaus D, Habermann W. Presenteeism: a review and research directions. Hum Resour Manag Rev. 2019;29(1):43-58.

6. Stewart WF, Ricci JA, Chee E, Morganstein D, Lipton R. Lost productive time and cost due to common pain conditions in the US workforce. JAMA. 2003;290(18):2443-54.

7. Prater T, Smith K. Underlying factors contributing to presenteeism and absenteeism. J Bus Econ Stat (JBER). 2011;9(6):1-14.

8. Gustafsson K, Bergström G, Marklund S, Aboagye E, Leineweber C. Presenteeism as a predictor of disability pension: a prospective study among nursing professionals and care assistants in Sweden. J Occup Health. 2019;61(6):453-63.

9. Hemp P. Presenteeism: at work-but out of it. Harv Bus Rev. 2004;82(10):49-58.

10. Niven K, Ciborowska N. The hidden dangers of attending work while unwell: a survey study of presenteeism among pharmacists. Int J Stress Manag. 2015;22(2):207.

11. Baldonedo-Mosteiro M, Sánchez-Zaballos M, Rodríguez-Díaz FJ, Herrero J, Mosteiro-Díaz MdP. Adaptation and validation of the Stanford Presenteeism Scale-6 in healthcare professionals. Int Nurs Rev. 2020;67(1):109-17.

12. Rainbow JG, Drake DA, Steege LM. Nurse health, work environment, presenteeism and patient safety. West J Nurs Res. 2020;42(5):332-9.

13. Cicolini G, Della Pelle C, Cerratti F, Franza M, Flacco ME. Validation of the Italian version of the Stanford Presenteeism Scale in nurses. J Nurs Manag. 2016;24(5):598-604.

14. Webster RK, Liu R, Karimullina K, Hall I, Amlôt R, Rubin GJ. A systematic review of infectious illness presenteeism: prevalence, reasons and risk factors. BMC Public Health. 2019;19(1):799.

15. Hayes B, Prihodova L, Walsh G, Doyle F, Doherty S. Doctors don't do-little: a national cross-sectional study of workplace well-being of hospital doctors in Ireland. BMJ open. 2019;9(3):e025433.

16. Li Y, Zhang J, Wang S, Guo S. The effect of presenteeism on productivity loss in nurses: the mediation of health and the moderation of general self-efficacy. Front Psychol. 2019;10:1745.

17. Murrells T, Robinson S, Griffiths P. Job satisfaction trends during nurses' early career. BMC Nurs. 2008;7(1):7.

18. Roy A, van der Weijden T, de Vries N. Relationships of work characteristics to job satisfaction, turnover intention, and burnout among doctors in the district public-private mixed health system of Bangladesh. BMC Health Serv Res. 2017;17(1):421

19. Toolib SN, Alwi MNR. Job satisfaction, job demand, workaholism and supervisor support on presenteeism: a pilot study using structural equation modeling approach. J Glob Bus Manag Res (GBMR). 2020;12(4):732-45.

20. Rodríguez-Cifuentes F, Fernández-Salinero S, Moriano JA, Topa G. Presenteeism, overcommitment, workplace bullying, and job satisfaction: a moderated mediation relationship. Int J Environ Res Public Health. 2020;17(22):8616

21. Aronsson G, Gustafsson K. Sickness presenteeism: prevalence, attendance-pressure factors, and an outline of a model for research. J Occup Environ Med. 2005:47(9):958-66.

22. Baker-McClearn D, Greasley K, Dale J, Griffith F. Absence management and presenteeism: the pressures on employees to attend work and the impact of attendance on performance. Hum Resour Manag J. 2010;20(3):311-28.

23. Gosselin E, Lemyre L, Corneil W. Presenteeism and absenteeism: differentiated understanding of related phenomena. J Occup Health Psychol. 2013;18(1):75

24. Côté K, Lauzier M, Stinglhamber F. The relationship between presenteeism and job satisfaction: a mediated moderation model using work engagement and perceived organizational support. Eur Manag J. 2021:39(2):270-8

25. Baeriswyl S, Krause A, Schwaninger A. Emotional exhaustion and job satisfaction in airport security officers-work-family conflict as mediator in the job demands-resources model. Front Psychol. 2016;7:663.

26. Blanch A. Social support as a mediator between job control and psychological strain. Soc Sci Med. 2016;157:148-55.
27. Panari C, Simbula S. Presenteeism, "on the desk." Int J Workplace Health Manag. 2016;9(1):84-95.

28. Vandenbroeck S, Van Gerven E, De Witte H, Vanhaecht K, Godderis $L$. Burnout in Belgian physicians and nurses. J Occup Med. 2017:67(7):546-54.

29. Demerouti E, Le Blanc PM, Bakker AB, Schaufeli WB, Hox J. Present but sick: a three-wave study on job demands, presenteeism and burnout. Career Dev Int. 2009;14(1):50-68.

30. Alcântara MA, Sampaio RF, Assuncao AA, Silva FCM. Work Ability: using structural equation modeling to assess the effects of aging, health and work on the population of Brazilian municipal employees. Work. 2014;49(3):465-72.

31. IImarinen J. The Work Ability Index (WAI). Occup Med. 2007;57(2):160.

32. Mehrdad R, Mazloumi A, Arshi S, Kazemi Z. Work ability index among healthcare personnel in a university hospital in Tehran, Iran. Work. 2016;53(4):851-7.

33. Derycke H, Clays E, Vlerick P, D'Hoore W, Hasselhorn HM, Braeckman L. Perceived work ability and turnover intentions: a prospective study among Belgian healthcare workers. J Adv Nurs. 2012;68(7):1556-66.

34. Palmlöf L, Skillgate E, Talbäck M, Josephson M, Vingård E, Holm L. Poor work ability increases sickness absence over 10 years. J Occup Med. 2019;69(5):359-65.

35. Gustafsson K, Marklund S. Consequences of sickness presence and sickness absence on health and work ability: a Swedish prospective cohort study. Int J Occup Med Environ Health. 2011;24(2):153-65.

36. Cadiz DM, Brady G, Rineer JR, Truxillo DM. A review and synthesis of the work ability literature. Work Aging Retire. 2019:5(1):114-38.

37. Terwee CB, Bot SD, de Boer MR, van der Windt DA, Knol DL, Dekker J, et al. Quality criteria were proposed for measurement properties of health status questionnaires. J Clin Epidemiol. 2007;60(1):34-42.

38. Bowling NA, Hammond GD. A meta-analytic examination of the construct validity of the Michigan Organizational Assessment Questionnaire Job Satisfaction Subscale. J Vocat Behav. 2008;73(1):63-77.

39. Mokarami H. Developing a model to explain turnover intention based on macroergonomics factors and role of fatigue and work ability index (WAI) as mediators. PhD thesis. Tarbiat Modares University, Occupational Health Engineering Department; 2016.

40. Mokarami H, Cousins R, Kalteh HO. Comparison of Work Ability Index and Work Ability Score for prediciting health-related quality of life. Int Arch Occup Environ Health. 2021. https://doi.org/10.1007/ s00420-021-01740-9.

41. Maslach C, Jackson SE. The measurement of experienced burnout. J Organ Behav. 1981;2(2):99-113.

42. Akbari R, Ghafar Samar R, Kiany GR, Eghtesadi AR. Factorial validity and psychometric properties of Maslach burnout inventory-the Persian version. Knowl Health. 2011;6(3):1-8.

43. Beaton DE, Bombardier C, Guillemin F, Ferraz MB. Guidelines for the process of cross-cultural adaptation of self-report measures. Spine. 2000;25(24):3186-91.

44. Polit DF, Beck CT, Owen SV. Is the CVI an acceptable indicator of content validity? Appraisal and recommendations. Res Nurs Health. 2007;30(4):459-67.

45. Lawshe $\mathrm{CH}$. A quantitative approach to content validity. Pers Psychol. 1975;28(4):563-75.

46. Maasoumi R, Mokarami H, Nazifi M, Stallones L, Taban A, Yazdani Aval $\mathrm{M}$, et al. Psychometric properties of the Persian translation of the sexual quality of life-male questionnaire. Am J Mens Health. 2017;11 (3):564-72.

47. Munro BH. Statistical methods for health care research. Lippincott Williams \& Wilkins; 2005.

48. Kinnunen U, Nätti J. Work ability score and future work ability as predictors of register-based disability pension and long-term sickness absence: a three-year follow-up study. Scand J Public Health. 2018;46(3):321-30.

49. Mannion A, Junge A, Fairbank J, Dvorak J, Grob D. Development of a German version of the Oswestry Disability Index. Part 1: cross-cultural adaptation, reliability, and validity. Eur Spine J. 2006;15(1):55-65.

50. Harris K, Lim CR, Dawson J, Fitzpatrick R, Beard DJ, Price AJ. The Oxford knee score and its subscales do not exhibit a ceiling or a floor effect in knee arthroplasty patients: an analysis of the National Health Service PROMs data set. Knee Surg Sports Traumatol Arthrosc. 2017:25(9):2736-42. 
51. Frauendorf R, de Medeiros PM, Ciconelli RM. Translation into Brazilian Portuguese, cross-cultural adaptation and validation of the Stanford presenteeism scale- 6 and work instability scale for ankylosing spondylitis. Clin Rheumatol. 2014;33(12):1751-7.

52. Laranjeira CA. Validation of the $P$ ortuguese version of the $S$ tanford $P$ resenteeism S cale in nurses. Int J Nurs Pract. 2013;19(6):644-50.

53. Hockey GRJ. Compensatory control in the regulation of human performance under stress and high workload: a cognitive-energetical framework. Biol Psychol. 1997:45(1-3):73-93.

54. Bergström G, Bodin L, Hagberg J, Lindh T, Aronsson G, Josephson M. Does sickness presenteeism have an impact on future general health? Int Arch Occup Environ Health. 2009;82(10):1179-90.

55. Prochnow A, Magnago TSBdS, Urbanetto JdS, Beck CLC, Lima SBSd, Greco PBT. Work ability in nursing: relationship with psychological demands and control over the work. Rev Latino-Am Enfermagem (RLAE). 2013;21(6):1298-305.

56. Heponiemi T, Kouvonen A, Sinervo T, Elovainio M. Is the public healthcare sector a more strenuous working environment than the private sector for a physician? Scand J Public Health. 2013;41(1):11-7.

57. Hobfoll SE. Conservation of resource caravans and engaged settings. J Occup Organ Psychol. 2011;84(1):116-22.

58. Johns G. Attendance dynamics at work: the antecedents and correlates of presenteeism, absenteeism, and productivity loss. J Occup Health Psychol. 2011;16(4):483.

\section{Publisher's Note}

Springer Nature remains neutral with regard to jurisdictional claims in published maps and institutional affiliations.
Ready to submit your research? Choose BMC and benefit from:

- fast, convenient online submission

- thorough peer review by experienced researchers in your field

- rapid publication on acceptance

- support for research data, including large and complex data types

- gold Open Access which fosters wider collaboration and increased citations

- maximum visibility for your research: over $100 \mathrm{M}$ website views per year

At BMC, research is always in progress.

Learn more biomedcentral.com/submissions 